\title{
US COVID-19 State Mortality and Case Progression - A Midterm Report Card
}

\author{
Vernon Wen-Hau Lin ${ }^{1, *}$, Daniel Lin ${ }^{2}$, Hugh Pforsich ${ }^{3}$, Xiaoming Zhang $^{4}$ \\ ${ }^{1}$ Physical Medicine and Rehabilitation Service, The Hershel "Woody" Williams VA Medical Center, Huntington, West Virginia, USA \\ ${ }^{2}$ Mechanical Engineering, University of California, Davis, California, USA \\ ${ }^{3}$ Accounting Department, California State University, Sacramento, California, USA \\ ${ }^{4}$ Neurological Institute, Cleveland Clinic Foundation, Cleveland, Ohio, USA
}

Email address:

Vernon.lin@va.gov (V. Wen-Hau L.), daniellin1228@gmail.com (D. Lin), pforsich@saclink.csus.edu (H. Pforsich), zhangx6@ecf.org (Xiaoming Zhang)

${ }^{*}$ Corresponding author

\section{To cite this article:}

Vernon Wen-Hau Lin, Daniel Lin, Hugh Pforsich, Xiaoming Zhang. US COVID-19 State Mortality and Case Progression - A Midterm Report Card. Science Journal of Clinical Medicine. Vol. 9, No. 3, 2020, pp. 58-67. doi: 10.11648/j.sjcm.20200903.14

Received: August 14, 2020; Accepted: September 8, 2020; Published: September 21, 2020

\begin{abstract}
The US is leading the world in terms of the number of deaths and cases due to COVID-19. After the end of the national lockdown, there has been a significant rise in both new cases and deaths associated with COVID-19-especially in the southern and western states. This study presents an interim report of each state (50 states, DC, and Puerto Rico), in terms of mortality rate (MR, the number of cumulative deaths per 100,000 population due to COVID-19 by July 15, 2020) and Case Rate Progression (CRP, the percent change in the number of cumulative cases per 100,000 population increased from May 31 to July 15, 2020). The study provided an A - F grade report card for each state when compared to one another. The results showed that the states that received F's in MR are the following (starting from the worst): New Jersey, New York, Massachusetts, Connecticut, Washington DC, Rhode Island, and Louisiana. The following states received F's in CRP (starting from the worst): Arizona, Florida, South Carolina, Texas, Idaho, Arkansas, Montana, Alaska, Nevada, and Oklahoma. A poor CRP grade reflects rampant increases in new COVID-19 cases, followed by resulting increases in hospitalization, health resource utilization, and mortality. Some prior high casualty states with MR grades of F (e.g. New York, New Jersey, and Connecticut) have maintained low new case counts and received A grades in CRP. They are exemplary in terms of COVID-19 state/region-wide response and public health efforts.
\end{abstract}

Keywords: Covid-19, Mortality Rate, Case Rate Progression, Report Card

\section{Introduction}

A new coronavirus infection affecting humans with pneumonia symptoms emerged in Wuhan of Hubei Province in China in December 2019. This new strand was isolated on January 7, 2020 and was named Severe Acute Respiratory Syndrome Coronavirus 2 (SARS-CoV-2) by the World Health Organization (WHO). The disease that this virus caused was named Novel Coronavirus Disease 2019 (COVID-19) on February 11, 2020. On March 11th, after there were more than 118,000 COVID-19 cases and over 4,000 deaths in 114 countries, the WHO declared it to be a pandemic. In addition to its impact on China, COVID-19 has affected other Asian countries and many European nations-most acutely Italy,
Spain, the United Kingdom, and France. At the same time, COVID-19 reached both shores of the US and other countries on the north and south American continents. By July 19, 2020, the approximate number of reported cases in the world reached over 14 million and contributed to nearly 600,000 deaths, affecting all six major regions monitored by the WHO. The following three countries led the world in terms of approximate cases and deaths: US (3.54 million cases, 137,674 deaths), Brazil (2.04 million cases, 77,851 deaths), India (1.07 million cases, 26,816 deaths) [1].

The first confirmed COVID-19 case in the US was reported on January 20, 2020 in Snohomish County, Washington, from a recent traveler to Wuhan, China [2]. On February 26, 2020, a US Department of State task force (the White House 
Coronavirus Task Force) was formed to coordinate and oversee the administration's efforts to monitor, prevent, contain, and mitigate the spread of COVID-19. Measures taken by the US administration have included: travel restrictions, warnings to the American public against local outbreaks (by the Center for Disease Control, CDC), encouragement of public and private partnership for developing and administrating tests by the Food and Drug Administration (FDA), recommendations to close schools and in-person instruction in public and private primary and secondary schools and universities, implementation of the Defense Production Act to produce medical equipment, and recommendations to practice social distancing and avoid any gatherings of more than ten people (starting in mid-March 2020) [3].

Among earlier reports, the following groups have been observed to have higher than normal case rates: residents, employees, and visitors of long-term care facilities $[4,5]$, people in correctional and detention centers [6], workers in meat and poultry processing facilities [7], and passengers and staff on cruise ships [8] and naval vessels [9]. Additional reports also showed incidences of super-spreader events, such as church choir practices [10], large family gatherings [11], or leisure activities during spring breaks from school [12]. Due to the initial national efforts to encourage or mandate shelter-in-place lockdown policies, the daily new COVID-19-related case rate reached a peak in early April at nearly 30,000 cases, then gradually declined to a daily rate of nearly 17,000 cases on May 26, 2020. Beginning in mid-May, the CDC and the White House began to encourage phased opening of businesses and institutions based upon data-driven conditions in each region or state. However, these guidelines were not strictly followed, and increased cases were observed in many states and counties. Instead of declining, new cases nationally have climbed significantly since early June and by mid-July, new cases nationally have reached over 75,000 per day, with the rate still climbing [13].

The principle aim of this manuscript is to provide an interim report in all 52 US states/jurisdictions (50 states plus Washington DC and Puerto Rico, hereafter referred to as states) with emphasis on the mortality rate (MR) per 100,000 population and recent progression of case rates from the initial lockdown up to the beginning of "phased openings" in the US. The percentage of increase in case rates between May 31 and July 15, 2020, or case rate progression (CRP), will be highlighted to warn the public and to encourage policymakers, health care providers, and other stakeholders, to adequately provide resources and to institute timely mitigating measures for preventing deteriorating consequences of the lingering and downward spiraling of US public health due to COVID-19. In other words, the MR can be used as a rearview mirror of what each state has done in combating the disease and the CRP can be used as our current view forward in order to navigate through this troubling time. A common grading system is used to compare the findings in all the states due to public familiarity.

Our research group-Health Care First Study Group-has been established with a mission to improve access to health care for Americans through relevant health service research and healthcare provider forecasts [14-16].

\section{Methodology}

\subsection{Design and Sample}

COVID-19 related state cases and mortality data were obtained from public sources such as respective state health department websites, the Center for Disease Control (CDC), and the New York Times (NYT). This midterm report card presents two types of grades for each state. The first grade is given to each state based upon the cumulative mortality rate (MR, \# of deaths per 100,000) each state reached by July 15, 2020. The second grade, Case Rate Progression (CRP) grade, was given based upon the percentage changes in case rates from May 31 to July 15, 2020.

\subsection{Mortality Rate (MR) Model}

The MR model was based on the number of COVID-19 certified deaths per state. The MR of each state is determined by the cumulative deaths by July 15, 2020 per 100,000. The MR was then utilized to give a grade to each state. The equation for the MR model is as follows:

$$
\mathrm{MR}_{\mathrm{s}}=([\text { July } 15 \text { State Cumulative Deaths }] /[\text { Pop }]) \times 10^{5}
$$

where $M_{\mathrm{s}}=$ Mortality Rate (MR) for each state; Pop = US Census Bureau (USCB) 2020 projected data.

\subsection{Mortality Rate (MR) Grade}

The grading method used for MR is the cumulative deaths (up to July 15, 2020) for each state per 100,000. Each state was given a grade based on the MR determined for each state. See the table below for the designated grade distributions associated with each state's MR and CRP calculation:

Table 1. Grade distribution for mortality rate (MR) and case rate progression $(C R P)$ in \% increased.

\begin{tabular}{lll}
\hline Grade & MR & CRP (\% Increased) \\
\hline A & $0-5.5$ & $0.0-25$ \\
B & $5.5-11.0$ & $25-45$ \\
C+ & $11.0-16.0$ & $45-80$ \\
C & $16.0-25.0$ & $80-110$ \\
C- & $25.0-40.0$ & $110-160$ \\
D & $40.0-70.0$ & $160-240$ \\
F & $70.0-170.0$ & $240-500$ \\
\hline
\end{tabular}

\subsection{Case Rate Progression (CRP) Model}

The Case Rate Progression (CRP) model was designed to monitor the rate of change in case rates in all states between May 31 and July 15, 2020. The case rate was defined as the number of COVID-19 cases cumulatively reported in a designated time. May 31, 2020 was chosen as the starting point because most states began lifting lockdown restrictions of businesses and public spaces by May 20, 2020. July 15, 2020 was the selected end date because a significant number of states had already observed significant spikes in reported case counts during the 
month of June through early July. A given state's CRP is defined by the percentage $(\%)$ increase in case rates from the beginning time point (May 31, 2020) to the ending time point (July 15, 2020). The equation for the CRP is as follows:

$$
\text { CRPs }=\left(\left[\left(J 15 / \text { Pop*105 }^{*} /(\mathrm{M} 31 / \text { Pop*105 })\right]-1\right)^{*} \times 100\right.
$$

Where CRPs $=$ Case Rate Progression (in \%) change per state; J15 = state positive COVID-19 cumulative case count on July 15, 2020; M31 = state positive COVID-19 cumulative case count on May 31, 2020; Pop = US Census Bureau (USCB) 2020 projected data.

\subsection{Case Rate Progression (CRP) Grade}

The CRP value, or percentage change in case rates from May 31 through July 15, 2020, was used to designate a grade for each state. Referring again to the table above, a given value of CRP calculated for each state corresponds with a designated letter grade, based upon the grade distribution assigned.

\subsection{Percent (\%) Positive in COVID-19 Testing}

Percent (\%) positives in COVID-19 test results were obtained from publicly available sources [17]. These were obtained for comparison purposes and for enhancing MR and CRP data analyses [17].

\section{Results}

The fifty states plus Washington DC and Puerto Rico were included in our analyses (Figure 1). Grading for MR showed that 7 states received $\mathrm{F}$ grades (MR greater than 70 per 100,000), namely (starting with the worst MR): New Jersey, New York, Massachusetts, Connecticut, Washington DC, Rhode Island, and Louisiana. The 6 states that received A grades (MR less than 5.5 per 100,000) were Hawaii (best), Alaska, Montana, Wyoming, Puerto Rico, and West Virginia. The following exhibit shows a full display of MR grades for the 52 states.

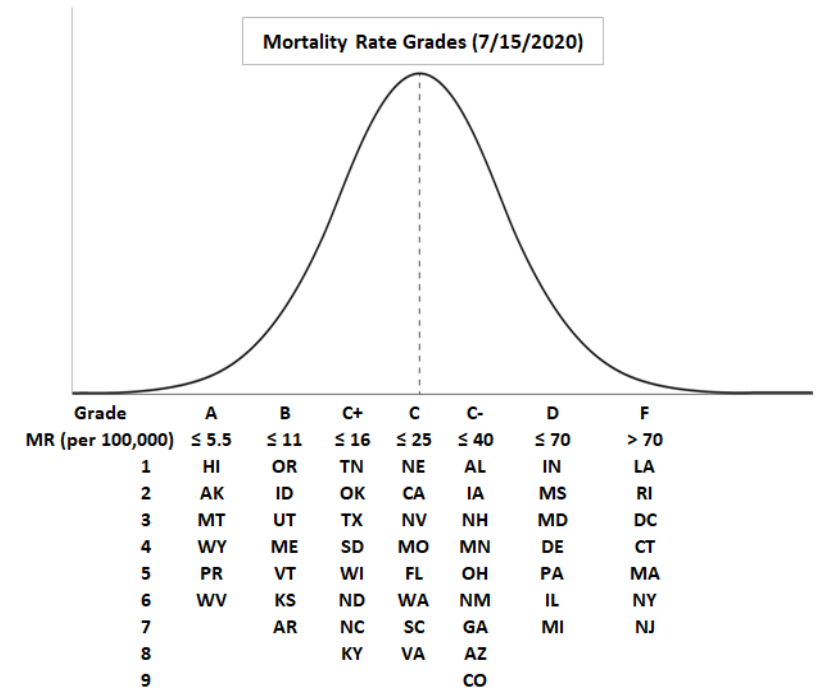

Figure 1. List of states (in abbreviation) with their associated grade in the Mortality Rate (MR) Report Card.
In terms of Case Rate Progression (CRP) as listed in Figure 2, $\mathrm{F}$ grades (showing a greater than $240 \%$ increase in CRP) were given to the following states (starting with the worst): Arizona, Florida, South Carolina, Texas, Idaho, Arkansas, Montana, Alaska, Nevada, and Oklahoma. An A grade (CRP less than $25 \%$ ) was given to New York (best), New Jersey, Connecticut, Massachusetts, Rhode Island, and Washington DC.

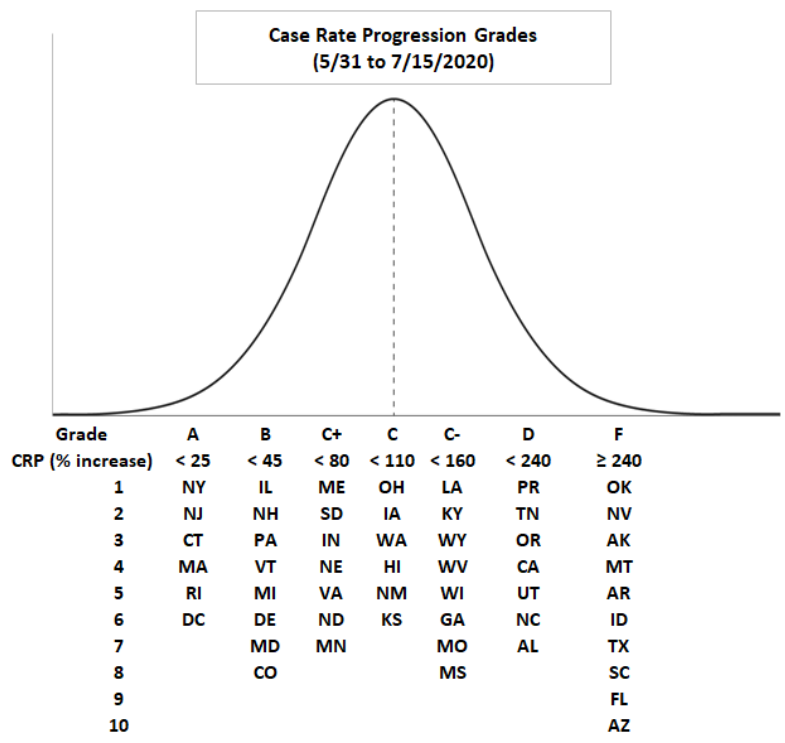

Figure 2. List of states (in abbreviation) with their associated grade in the Case Rate Progression (CRP) Report Card.

\section{Discussion}

\subsection{Mortality Rate (MR)}

US COVID-19 cases initially started on the West Coast, with the states of Washington and California reporting the earliest cases with associated mortality. Soon, cases began to multiply in the Northeastern states, with New York City being the epicenter. According to our assessment, by mid-July 2020, the states with the highest mortality rate (F grade designations) due to COVID-19 in the US were the following states in descending order: New Jersey (worst), New York, Massachusetts, Connecticut, Washington DC, Rhode Island, and Louisiana. New Jersey led the country with an MR of 165 deaths per 100,000 - with nearly 179,000 cases and 15,684 deaths reported by mid-July. The daily death rate in New Jersey peaked at 379 on April 21, 2020 and has steadily declined due to efforts by residents and all levels of government. Similarly, by mid-July New York reached approximately 225,000 reported cases, 22,848 deaths, and an MR of 164 per 100,000 . The daily death rate in New York peaked at 800 on April 14, 2020 and has steadily declined and reached zero daily fatalities on July 11, 2020.

During this period, the other Northeastern states closely followed. Massachusetts reached nearly 113,000 cases and 8,402 deaths, with an MR of 122 per 100,000 and Connecticut had 47,893 cases and 4,396 deaths, with an MR of 119 per 100,000 . Nearly 50 percent of these deaths were attributed to nursing home residents. Washington DC had 11,115 
confirmed cases, and 577 deaths, with an MR of 119 per 100,000. Rhode Island had 17,793 confirmed cases and 990 deaths, with an MR of 86 per 100,000.

By mid-July, the only state not on the East Coast that received an F grade in MR was Louisiana, with 73 deaths per 100,000. This apparent anomaly was partly due to: 1) New Orleans being an international travel destination with an international airport, 2) Mardi Gras taking place in February 2020 with many attractive venues involving specialty foods and large gatherings of people, and 3) relatively high comorbidities and chronic health conditions in Louisiana residents. Louisiana's rate of new cases per day has risen steadily since early June and reached 2,179 on July 17, 2020. This prompted the governor to issue a face-covering mandate for all people over the age of 8 and gatherings over 50 people were not allowed [18].

The next category of states that had relatively high mortality rates and received the D grades included: Michigan, Illinois, Pennsylvania, Delaware, Maryland, Mississippi, and Indiana. Researchers have generally attributed the initial explosions of COVID-19 cases in the US Northeast to travelers mostly coming from Europe months earlier. Soon, midwestern cities with international destinations, such as Chicago and Detroit, became hot spots as well, with Chicago's Cook County Jail becoming one of the largest single sources of infection in the country [19]. The greater Detroit area also saw significant community spread and associated mortality, especially in African American communities. While this demographic group makes up only 14 percent of the population, it suffered 40 percent of the virus mortality. A CDC report on Detroit's 26 nursing homes, showed 44 percent of confirmed COVID-19 cases with a 37 percent hospitalization rate and a 24 percent fatality rate among the 2,773 residents tested [5]

\subsection{Case Rate Progression (CRP)}

Starting in mid-May 2020, the country began to gradually loosen the lockdown on the economy with the CDC providing guidance for phased re-opening in various business and religious venues based upon infection rates and the number of new cases. Many states that experienced relatively low death rates previously, had more rapid opening scenarios that led to significant rises in new cases. This resulted in significant increases in hospitalizations and associated deaths. According to our calculations, the following states had the highest percentage rise in case rate progression (CRP) between May 31 and July 15, 2020: Arizona, Florida, South Carolina, and Texas.

\subsubsection{Arizona}

By mid-July 2020, Arizona had accumulated 139,000 cases and over 2,596 reported deaths. The highest death tolls were in Maricopa County (1,374 deaths) and Pima County (367 deaths). There have also been reports that hospital and ICU capacities in these counties were under extreme duress and refrigerated trucks were sent in to serve as temporary morgues. Presently, Arizona is leading the nation with the highest positivity rate $(23.56 \%)$ for COVID-19. The positivity rate is the number of positive COVID-19 test results out of all tests conducted. A high positivity rate (over 5\%) may indicate that only the sickest patients who seek medical attention are being tested, whereas a low positivity rate (under 5\%) may signal that a sufficient number of tests are being done to inform decision-makers about the safety of reopening a particular region [17].

\subsubsection{Florida}

Florida saw the most significant rise in the number of cases for any state on record, with daily reported new cases of 15,300 on July 12,2020 , eclipsing the previous high of 12,274 recorded in New York on April 4, 2020. Now, Miami has been regarded as the new epicenter of the pandemic in the United States. The state of Florida had a cumulative 327,000 cases and 4,804 deaths by mid-July with the most affected counties were Miami-Dade, Palm Beach, and Broward [21]. Florida surpassed New York in coronavirus cases on July 26, the second-highest number of cases in the country behind only California. Florida is also ranked third in the positivity rate (18.72\%) for COVID-19 [17]. Again, this reflects the inadequacy of testing in the state where patients with symptoms were preferentially given opportunities to be tested. High new case rates are being followed by high hospital admissions, ICU admissions, and mortalities.

\subsubsection{South Carolina}

South Carolina recently reached 66,060 cases with 1,096 deaths. The counties with the highest deaths are Greenville and Richland. The COVID-19 positivity rate for South Carolina was 15.71 percent [17].

\subsubsection{Texas}

Another populous southern state with a significant rise in COVID-19 cases and deaths in recent weeks is Texas with roughly 319,000 cumulative cases and 3,834 deaths by July 17 , 2020 [20]. Harris (Greater Houston) and Dallas counties have reported over 500 COVID-19-related deaths in each county. The federal government is sending military medical personnel to assist in managing the increased healthcare demand in Texas [21]. The positivity rate in Texas was 15.1 percent [17].

The statistics for the remaining states that received $\mathrm{F}$ grades in CRP are Idaho (13,326 cases and 114 deaths; $18.15 \%$ positivity), Arkansas (32,533 cases and 357 deaths, $11.33 \%$ positivity), Montana (2,383 cases and 37 deaths, $4.19 \%$ positivity), Alaska (2,079 cases and 15 deaths, $2.9 \%$ positivity), Nevada (34,606 cases and 647 deaths, 19.14\% positivity), and Oklahoma (6,195 cases and 77 deaths, 9.04\% positivity).

Though many of the above states were small in population when compared with some prior states, they all shared the trend of significant increases in cases in recent weeks (greater than $240 \%$ ). Some of the above states mentioned have implemented mandatory face-covering policies and began either paused openings, phased openings, or the implementation of stricter social gathering and business-opening policies [22]. Due to these states' significant 
rise in cases in recent weeks, their mortality rates are expected to rise accordingly.

The states that received D grades for CRP included some southern and western states, among which included the most populous state, California. Although California started their statewide lockdown early, the curve of COVID-19 cases over time was not significantly delayed. By July 17, 2020, the state accumulated 337,000 cases and 7,102 deaths, with Los Angeles County leading the number of deaths, followed by Riverside County, Orange County, and San Diego County. On July 21, 2020, California surpassed New York as the state with the most recorded COVID-19 cases $(409,300)$ [20].

Some of the states with the highest MR early on (received F grades), such as the Northeastern states, were able to flatten their curves and received A grades in terms of CRP: New York ( $8.8 \%, 1.15 \%$ positive), New Jersey $(11.1 \%, 1.41 \%$ positive $)$, Connecticut (11.4\%, 0.84\% positive), Massachusetts (15.6\%, $2.33 \%$ positive), Rhode Island (17.9\%, 3.83\% positive), and Washington DC $(24.5 \%, 1.98 \%$ positive). Most of these states had experienced tremendous hardship during the earlier COVID-19 peak period in April 2020 but appeared to have learned important lessons to significantly improve their CRPs and positivity rates.

The following table shows the MR and CRP data and grades as well as the positivity statistics for each state in alphabetical order:

Table 2. List of 50 US states and two jurisdictions (DC \& Puerto Rico), and their respective, mortality rate (MR), Case Rate Progression (CRP), and \% positive in testing for COVID-19. (Listed in alphabetical order for each state/jurisdiction, abbreviation of each state, actual MR number, state ranking based on MR, grade based on MR, actual CRP (\% increased from May 31 to July 15, 2020), state ranking based on CRP, grade based on CRP, and \% positive in testing).

\begin{tabular}{|c|c|c|c|c|c|c|c|c|c|}
\hline \# & State & $\begin{array}{l}\text { State } \\
\text { Abbrev. }\end{array}$ & $\begin{array}{l}\text { 7/15/2020 } \\
\text { MR \% } \\
\end{array}$ & $\begin{array}{l}\text { MR } \\
\text { Ranking }\end{array}$ & $\begin{array}{l}\text { MR } \\
\text { Grade }\end{array}$ & $\begin{array}{l}\text { 7/15/2020 } \\
\text { CRP \% }\end{array}$ & $\begin{array}{l}\text { CRP } \\
\text { Rank }\end{array}$ & $\begin{array}{l}\text { CRP } \\
\text { Grade }\end{array}$ & $\begin{array}{l}\text { 7/20/2020 } \\
\text { Positivity \% }\end{array}$ \\
\hline 1 & Alabama & $\mathrm{AL}$ & 25.61 & 30 & C- & 228.15 & 42 & $\mathrm{D}$ & 18.13 \\
\hline 2 & Alaska & $\mathrm{AK}$ & 1.94 & 2 & $\mathrm{~A}$ & 316.63 & 45 & $\mathrm{~F}$ & 2.90 \\
\hline 3 & Arizona & $\mathrm{AZ}$ & 28.88 & 37 & $\mathrm{C}-$ & 456.40 & 52 & $\mathrm{~F}$ & 23.56 \\
\hline 4 & Arkansas & AR & 10.95 & 13 & B & 317.72 & 47 & $\mathrm{~F}$ & 11.33 \\
\hline 5 & California & $\mathrm{CA}$ & 17.46 & 23 & $\mathrm{C}$ & 214.28 & 39 & $\mathrm{D}$ & 7.26 \\
\hline 6 & Colorado & $\mathrm{CO}$ & 33.06 & 38 & $\mathrm{C}-$ & 44.97 & 14 & B & 7.29 \\
\hline 8 & Delaware & $\mathrm{DE}$ & 54.09 & 42 & $\mathrm{D}$ & 37.31 & 12 & B & 4.59 \\
\hline 9 & Florida & FL & 19.31 & 26 & $\mathrm{C}$ & 427.72 & 51 & $\mathrm{~F}$ & 18.72 \\
\hline 10 & Georgia & GA & 27.94 & 36 & $\mathrm{C}-$ & 137.66 & 33 & $\mathrm{C}-$ & 15.24 \\
\hline 11 & Hawaii & HI & 1.49 & 1 & A & 97.98 & 25 & $\mathrm{C}$ & 1.44 \\
\hline 12 & Idaho & ID & 6.37 & 8 & B & 335.05 & 48 & $\mathrm{~F}$ & 18.15 \\
\hline 13 & Illinois & IL & 56.17 & 44 & $\mathrm{D}$ & 31.40 & 7 & B & 2.94 \\
\hline 14 & Indiana & IN & 42.02 & 39 & $\mathrm{D}$ & 54.39 & 17 & $\mathrm{C}+$ & 7.97 \\
\hline 17 & Kentucky & $\mathrm{KY}$ & 15.10 & 21 & $\mathrm{C}+$ & 112.82 & 29 & $\mathrm{C}-$ & 5.37 \\
\hline 18 & Louisiana & LA & 73.34 & 46 & $\mathrm{~F}$ & 110.49 & 28 & $\mathrm{C}-$ & 10.17 \\
\hline 19 & Maine & $\mathrm{ME}$ & 8.09 & 10 & B & 53.17 & 15 & $\mathrm{C}+$ & 0.98 \\
\hline 20 & Maryland & MD & 51.42 & 41 & $\mathrm{D}$ & 41.38 & 13 & B & 5.21 \\
\hline 21 & Massachusetts & MA & 122.06 & 50 & $\mathrm{~F}$ & 15.56 & 4 & A & 2.33 \\
\hline 22 & Michigan & MI & 59.21 & 45 & $\mathrm{D}$ & 35.14 & 11 & B & 2.70 \\
\hline 23 & Minnesota & $\mathrm{MN}$ & 26.40 & 33 & $\mathrm{C}-$ & 76.11 & 21 & $\mathrm{C}+$ & 4.00 \\
\hline 24 & Mississippi & MS & 42.37 & 40 & $\mathrm{D}$ & 148.80 & 35 & $\mathrm{C}-$ & 14.82 \\
\hline 25 & Missouri & MO & 18.40 & 25 & $\mathrm{C}$ & 138.68 & 34 & $\mathrm{C}-$ & 7.68 \\
\hline 26 & Montana & MT & 3.32 & 3 & A & 317.28 & 46 & $\mathrm{~F}$ & 4.19 \\
\hline 27 & Nebraska & $\mathrm{NE}$ & 16.75 & 22 & $\mathrm{C}$ & 55.87 & 18 & $\mathrm{C}+$ & 6.10 \\
\hline 28 & Nevada & NV & 17.93 & 24 & $\mathrm{C}$ & 252.06 & 44 & $\mathrm{~F}$ & 19.14 \\
\hline 29 & New Hampshire & $\mathrm{NH}$ & 25.84 & 32 & $\mathrm{C}-$ & 31.43 & 8 & B & 1.79 \\
\hline 30 & New Jersey & NJ & 165.24 & 52 & $\mathrm{~F}$ & 11.10 & 2 & A & 1.41 \\
\hline 31 & New Mexico & NM & 26.72 & 35 & $\mathrm{C}-$ & 106.02 & 26 & $\mathrm{C}$ & 3.93 \\
\hline 34 & North Dakota & ND & 14.60 & 19 & $\mathrm{C}+$ & 74.19 & 20 & $\mathrm{C}+$ & 6.02 \\
\hline 35 & Ohio & $\mathrm{OH}$ & 26.41 & 34 & $\mathrm{C}-$ & 82.10 & 22 & $\mathrm{C}$ & 5.97 \\
\hline 36 & Oklahoma & OK & 11.56 & 15 & $\mathrm{C}+$ & 250.65 & 43 & $\mathrm{~F}$ & 9.04 \\
\hline 37 & Oregon & OR & 5.84 & 7 & B & 208.44 & 38 & $\mathrm{D}$ & 6.11 \\
\hline 38 & Pennsylvania & PA & 54.83 & 43 & $\mathrm{D}$ & 34.30 & 9 & B & 5.59 \\
\hline 39 & Puerto Rico & PR & 5.35 & 5 & A & 174.87 & 36 & $\mathrm{D}$ & 100.00 \\
\hline 40 & Rhode Island & RI & 85.51 & 47 & $\mathrm{~F}$ & 17.90 & 5 & A & 3.83 \\
\hline 41 & South Carolina & $\mathrm{SC}$ & 20.69 & 28 & $\mathrm{C}$ & 424.79 & 50 & $\mathrm{~F}$ & 15.71 \\
\hline 42 & South Dakota & SD & 13.84 & 17 & $\mathrm{C}+$ & 53.25 & 16 & $\mathrm{C}+$ & 5.44 \\
\hline 43 & Tennessee & $\mathrm{TN}$ & 11.40 & 14 & $\mathrm{C}+$ & 195.70 & 37 & $\mathrm{D}$ & 9.01 \\
\hline 44 & Texas & TX & 12.51 & 16 & $\mathrm{C}+$ & 354.68 & 49 & $\mathrm{~F}$ & 15.10 \\
\hline 45 & Utah & UT & 7.79 & 9 & B & 217.71 & 40 & $\mathrm{D}$ & 9.31 \\
\hline 46 & Vermont & VT & 8.11 & 11 & $\mathrm{~B}$ & 34.35 & 10 & $\mathrm{~B}$ & 0.81 \\
\hline
\end{tabular}




\begin{tabular}{llllllllll}
\hline$\#$ & \multirow{2}{*}{ State } & $\begin{array}{l}\text { State } \\
\text { Abbrev. }\end{array}$ & $\begin{array}{l}\mathbf{7 / 1 5} / \mathbf{2 0 2 0} \\
\text { MR } \%\end{array}$ & $\begin{array}{l}\text { MR } \\
\text { Ranking }\end{array}$ & $\begin{array}{l}\text { MR } \\
\text { Grade }\end{array}$ & $\begin{array}{l}\mathbf{7 / 1 5 / 2 0 2 0} \\
\text { CRP \% }\end{array}$ & $\begin{array}{l}\text { CRP } \\
\text { Rank }\end{array}$ & $\begin{array}{l}\text { CRP } \\
\text { Grade }\end{array}$ & $\begin{array}{l}\mathbf{7 / 2 0} / \mathbf{2 0 2 0} \\
\text { Positivity \% }\end{array}$ \\
\hline 47 & Virginia & VA & 22.34 & 29 & C & 64.83 & 19 & C+ & 6.54 \\
48 & Washington & WA & 19.99 & 27 & C & 97.26 & 24 & C & 5.52 \\
49 & Washington DC & DC & 118.82 & 48 & F & 24.49 & 6 & A & 1.98 \\
50 & West Virginia & WV & 5.44 & 6 & A & 126.72 & 31 & C- & 3.49 \\
51 & Wisconsin & WI & 13.91 & 18 & C + & 130.26 & 32 & C- & 7.26 \\
52 & Wyoming & WY & 4.14 & 4 & A & 119.82 & 30 & C- & 6.42 \\
\hline
\end{tabular}

\subsection{Key Characteristics}

A recent $\mathrm{CDC}$ report revealed the following statistics on COVID-19 decedents in the US [23]: 55.4 percent male, 79.6 percent over 65 years old, 40.3 percent White, 21.0 percent Black, 13.8 percent Hispanic, and 3.9 percent Asian. The median decedent age was 78 years. Overall, the most common underlying medical conditions of the decedents were cardiovascular diseases $(70 \%)$, diabetes mellitus $(40 \%)$, chronic kidney disease (21\%), and chronic lung disease (19\%). The median interval from illness onset to death was 10 days. From those that were hospitalized, the median interval from hospital admission to death was 5 days.

When comparing various ethnic groups, this study also revealed the relatively high percentages of Hispanic and nonwhite decedents under 65 years old to be notable. The median age of nonwhite persons (31 years) in the US general population is lower than that of white persons (44 years). These differences might help explain the higher proportions of Hispanic and nonwhite COVID-19 decedents among those under 65 years old. The median ages among Hispanic and nonwhite decedents (71 and 72 years, respectively) were 9-10 years, lower than that of white decedents ( 81 years). It is possible that the transmission of COVID-19 is higher among Hispanic and nonwhite persons under 65 years old than among white persons. One potential contributing factor is higher percentages of Hispanic and nonwhite persons engaged in occupations (e.g., service industry, or nursing homes) or essential activities that preclude physical distancing [23]. As the recent surge in COVID-19 cases in the Southern states continues, the rise in Hispanic and nonwhite population mortality is expected to follow as well.

\subsection{Clinical Course}

Another CDC report [24] showed the symptom profiles of patients with COVID-19, which included: cough (84\%), fever $(80 \%)$, myalgia (63\%), chills (63\%), fatigue $(62 \%)$, headache $(59 \%)$, shortness of breath (57\%), and GI symptoms $(50 \%)$ such as diarrhea and vomiting. These were collected from 16 states and 164 patients. The median age was 50 years, 56 percent were male, 90 percent were not hospitalized, and 10 percent were less than the age of 18. All the patients hospitalized were adults. Another publication showed that 19 percent required non-invasive ventilation, 17 percent required intensive care, 9 percent required invasive ventilation, 2 percent required extracorporeal membrane oxygenation, and the mortality rate was 7 percent [25].

Other clinical reports showed that severe diseases among
COVID-19 patients were associated with higher white blood cell and neutrophil counts, C-reactive protein, lactate dehydrogenase, D-dimer, and aspartate aminotransferase [26, 27]. Additionally, CT imaging displayed ground-glass opacification patterns $(80 \%)$ as well as bilateral involvement (69\%). Eventual progression to acute respiratory distress syndrome (ARDS) was the most common complication of patients with COVID-19 [27]. In another meta-analysis, the mean lengths of time from COVID-19 exposure stage by stage to either recovery or death are as follows: the incubation period was 5.7 days, the onset of symptoms to first clinic visit was 4.9 days, ICU admission was 9.8 days, recovery was 18.6 days, and death was 15.9 days [25].

For the pediatric population, there were many reports of multisystem inflammatory syndrome. One report showed 95 confirmed cases from New York State, 31 percent ages 0-5, 42 percent ages 6-12, and 26 percent ages 13-20. All children presented with fever or chills, tachycardia (97\%), gastrointestinal symptoms $(80 \%)$, rash $(60 \%)$, conjunctival injection (56\%), and mucosal changes (27\%). Elevated C-reactive protein $(100 \%)$, D-dimer $(91 \%)$, and troponin (71\%) were found in these cases. About 62 percent received vasopressor support, 53 percent had evidence of myocarditis, 80 percent were admitted to an intensive care unit, and 2 died. The median length of hospital stay was 6 days [28].

An autopsy study on 12 subjects who died of COVID-19 showed deep venous thrombosis in 7 of 12 patients, none of whom were suspected of venous thrombosis before death. Pulmonary embolism was the direct cause of death in 4 of the patients. Postmortem-computed tomography revealed reticular infiltration of the lungs with severe bilateral, dense consolidation, whereas histomorphologically diffuse alveolar damage was seen in 8 of the patients. In all 12 patients, SARS-CoV-2 RNA was detected in the lung at high concentrations, viremia in 6 of them, and 5 demonstrated high viral RNA titers in the liver, kidney, or heart [29].

\subsection{Advances in Therapy}

The eventual definitive treatment will be an effective vaccine and there are many laboratories around the world working on such a cure. According to recent reports, three vaccines have demonstrated clinical potentials: 1) ChAdOx1nCoV-19: a chimpanzee adenovirus vectored vaccine, completed phases 1 and 2 of clinical trials-demonstrated T-cell responses, anti-spike $\operatorname{IgG}$ responses, and neutralizing antibody response against SARS-CoV-2 [30]; 2) Recombinant adenovirus type-5-vectored COVID-19 vaccine: completed a randomized, double-blind, placebo-controlled phase 3 clinical 
trial-demonstrated significant neutralizing antibody responses to live SARS-CoV-2 and will be considered for further development [31, 32]; 3) mRNA-1273 vaccine completed the Phase 1 trial; and reports showed no serious adverse events; and an interim analysis showed vaccine-induced neutralizing activity through day 43 after the second injection; and two doses of vaccine prompted high levels of neutralizing antibody activity that were above the average values seen in convalescent sera obtained from person with confirmed COVID-19 disease [33]. Once a safe vaccine is developed, one important question will be how long it will remain effective to protect the host. There have been reports of re-infection with SARS-CoV-2 after a period of recovery period from a prior infection and the natural human immune response may provide as short as 80 days of protection [34].

Other advances in therapies included: 1) Cellular therapies (Mesenchymal stem cells) and convalescent plasma-had favorable reports showing shorter hospital stays and lower mortality rates [35]; 2) anti-inflammatory/anti-allergic agents and immune-suppressants (Meplazumab, Fingolimod, Bevacizumab, Baricitinib, Tranilast, and Tozumab+adamumaab) [36]; 3) Antivirals (Remdesivir was shown to reduce the recovery time and mortality in a preliminary clinical trial [37]. Favipiravir is a viral RNA polymerase inhibitor, effective against influenza viruses and other RNA viruses, and is potentially promising. Other important negative findings: Lopinavir-ritonavir showed no significant benefit in mortality and ARDS rates in COVID-19 patients [38]. Antimalarial drugs such as hydroxychloroquine and chloroquine also demonstrated some antiviral activity against RNA viruses, however, they have not been proven to be effective against COVID-19 and were associated with higher mortality [39].

A randomized evaluation of dexamethasone in patients with COVID-19 showed significantly reduced lengths of hospitalization and mortality in patients receiving invasive mechanical ventilation as well as in those receiving oxygen without invasive mechanical ventilation [40].

\subsection{Public Health Considerations}

The resurgence of COVID-19 cases after the phased openings in some states has resulted in increased tension in state governments and has placed a tremendous burden on both policymakers and healthcare providers. Many public health servants, such as state or county health department directors, have been forced to resign due to deteriorating health conditions in their jurisdictions, and in some cases due to threats of personal safety. While the scientists are working on the cure/vaccine, reducing the rate of infection (flattening the curve) again is the only way for the US to weather through this pandemic storm and to bring about economic recovery. The following questions are presented to all of us in the coming months. First, do we have the collective public will to combat this disease and harness all resources available? States that are getting $\mathrm{F}$ grades now in CRP, may need to learn lessons from the Northeastern states, such as New York, New Jersey, and Connecticut; these states have tamed the storm by working together and mobilizing resources collectively. They instituted statewide physical distancing and hand hygiene protocols, mandated face masks early (April $15^{\text {th }}$ in the case of New York State), and limited social gathering and business activities. In addition, they increased the supply of personal protection equipment, ICU capacities, hired healthcare providers and supporting personnel from outside of the region, Online)• /•

equipment, such as ventilators, to areas that have the most needs. As a result, they have flattened the curve, and now are able to manage this disease through contact tracing and case management.

Second, is there adequate COVID-19 testing capacity in our community? Unfortunately, in the states that are graded D or F in CRP, the answer is a negative one. Many of these states have percent positive in the double digits $(>10 \%)$, at least twice the number recommended by WHO (5\% or lower). Higher percent positive not only indicates more cases in the community but also reflects that these states are preferentially selecting subjects with worse symptoms for testing and have limited testing capacities.

Thirdly, has our community successfully implemented physical distancing, mask-wearing, and hand hygiene guidelines? SARS-CoV-2 spreads person-to-person through close contact so prevention will rely on non-pharmaceutical interventions. Physical distancing, face masks, and eye protection to prevent person-to-person transmission of COVID-19 have been reviewed through a meta-analysis from 172 observational studies ( $\mathrm{n}=25,697$ patients) across 16 countries and 6 continents. Transmission of viruses was lower with physical distancing of 1 meter (3.3 feet) or more, compared with a distance less than 1 meter-protection was increased as distance was lengthened. Face mask use could result in a large reduction in risk of infection with a stronger association with N95 masks or similar respirators compared to disposable surgical masks or the like. Eye protection was also associated with less infection [41].

\subsection{Limitations of the Study}

The first limitation of this study is the potential for misinterpretation of the grading system. By placing all the states along a bell curve and giving a grade to each state, a false sense of security or accomplishment may be concluded by those states that have done well (e.g., were graded A, B, or C), from either the MR or CRP perspective. Neither grade accounts for the detailed effects of the virus on individual victims or the overall health of each state's population. Each patient that tested positive for COVID-19 may have different outcomes due to the timing and duration of the incubation period, symptom manifestation, clinic visit and/or hospitalization, ICU admission, and eventually either recovery or death. Also, depending upon the demographic characteristics of those that tested positive, the acuity of COVID-19's impact on the population is not specifically evaluated by these grades. For example, if the ones tested positive are young and healthy, the expected outcome will be much better than if they are elderly and have comorbidities. 
A second limitation of this study is that the MR and CRP grades only evaluate the success of a state from a purely public health policy perspective. The broader adverse consequences to a population caused by a blanket lockdown policy for all members of society for months at a time may be both psychological and economical and were not considered in this study.

Third, the financial status of a certain state may have affected its CRP grade. Some states that had the resources to provide more tests to their population may have increased their number of reported cases and therefore received a poorer CRP grade, deservedly so. At the same time, other states that lacked the resources to provide more testing may have had fewer reported cases and therefore received a higher CRP grade than deserved because positive cases in their population have never been tested or reported.

Finally, the public data collected and used in this study, as with all publicly reported data, may have validity issues. If significantly different criteria were used from state to state or from county to county to certify COVID-19 as the cause of death, the validity of the MR grades may be questioned. Similar concerns may apply to the CRP and positivity rate data.

\section{Conclusion}

This is an interim report card on how US states have embraced the ravages of COVID-19 from the beginning of the year through July 15, 2020. During the initial wave of infections and deaths, states in the northeastern region, such as, New Jersey, New York, Massachusetts, and Connecticut led the nation with the highest infection rates, and received the worst mortality rate grade (Grade F). In late May, as the US began phased openings, these northeastern states improved dramatically (Grade A) in terms of case rate progression (CRP). In contrast, Arizona, Florida, South Carolina, and Texas had average mortality rates but led the nation in CRP (Grade F). Now, as the country is confronted with decisions to open schools and other segments of economy, the following three questions need to be asked: Do we have the collective public will to combat this disease and harness all resources available? Is there adequate COVID-19 testing capacity in our community? Has our community successfully implemented physical distancing, mask-wearing, and hand hygiene guidelines? If our community is not certain about these necessary safeguards and preparations, our residents, neighbors, and loved ones will continue to pay a dear price, sometimes with their own lives, while we are waiting for a cure.

\section{References}

[1] World Health Organization, Coronavirus disease (COVID-2019) situation report -181, World Health Organization, Geneva 2020, https://www.who.int/docs/default-source/coronaviruse/situatio n-reports/20200719-covid-19-sitrep-181.pdf?sfvrsn=8235249 6_2, Accessed July 28, 2020.
[2] Holshue ML, DeBolt C, Lindquist S, et al. First Case of 2019 Novel Coronavirus in the United States. N Engl J Med. 2020; 382 (10): 929-936. doi: 10.1056/NEJMoa2001191.

[3] The white house, 30 days to slow the spread, the president's coronavirus guideline for America, https://www.whitehouse.gov/wp-content/uploads/2020/03/03. 16.20_coronavirus-guidance_8.5x11_315PM.pdf\#: :text=PR ACTICE GOOD HYGIENE: AVOID, Avoid touching your face, Accessed July 28, 2020.

[4] McMichael TM, Currie DW, Clark S, et al. Epidemiology of Covid-19 in a Long-Term Care Facility in King County, Washington. N Engl J Med. 2020; 382 (21): 2005-2011. doi: 10.1056/NEJMoa2005412.

[5] Sanchez GV, Biedron C, Fink LR, et al. Initial and Repeated Point Prevalence Surveys to Inform SARS-CoV-2 Infection Prevention in 26 Skilled Nursing Facilities - Detroit, Michigan, March-May 2020. MMWR Morb Mortal Wkly Rep 2020; 69: 882-886. DOI: http://dx.doi.org/10.15585/mmwr.mm6927e1

[6] Wallace M, Hagan L, Curran KG, et al. COVID-19 in Correctional and Detention Facilities - United States, February-April 2020. MMWR Morb Mortal Wkly Rep 2020; 69: $\quad 587-590 . \quad$ DOI: http://dx.doi.org/10.15585/mmwr.mm6919e1

[7] Dyal JW, Grant MP, Broadwater K, et al. COVID-19 Among Workers in Meat and Poultry Processing Facilities - 19 States, April 2020. MMWR Morb Mortal Wkly Rep. 2020; 69 (18): Published 2020 May 8. doi: 10.15585/mmwr.mm6918e3.

[8] Moriarty LF, Plucinski MM, Marston BJ, et al. Public Health Responses to COVID-19 Outbreaks on Cruise Ships Worldwide, February-March 2020. MMWR Morb Mortal Wkly Rep 2020; 69: 347-352. DOI:

http://dx.doi.org/10.15585/mmwr.mm6912e3

[9] Payne DC, Smith-Jeffcoat SE, Nowak G, et al. SARS-CoV-2 Infections and Serologic Responses from a Sample of U.S. Navy Service Members - USS Theodore Roosevelt, April 2020. MMWR Morb Mortal Wkly Rep 2020; 69: 714-721. DOI: http://dx.doi.org/10.15585/mmwr.mm6923e4externalicon

[10] Hamner L, Dubbel P, Capron I, et al. High SARS-CoV-2 Attack Rate Following Exposure at a Choir Practice - Skagit County, Washington, March 2020. MMWR Morb Mortal Wkly Rep 2020; 69: 606-610. DOI: http://dx.doi.org/10.15585/mmwr.mm6919e6external icon.

[11] Ghinai I, Woods S, Ritger KA, et al. Community Transmission of SARS-CoV-2 at Two Family Gatherings - Chicago, Illinois, February-March 2020. MMWR Morb Mortal Wkly Rep. 2020; 69 (15): 446-450. Published 2020 Apr 17. doi: 10.15585/mmwr.mm6915e1.

[12] Lewis M; Sanchez R2; Auerbach S et al, COVID-19 Outbreak Among College Students After a Spring Break Trip to Mexico Austin, Texas, March 26-April 5, 2020. MMWR Morb Mortal Wkly Rep. 2020; 69 (26): 830-835. Published 2020 Jul 3. doi: 10.15585/mmwr.mm6926e1.

[13] Centers for Disease Control and Prevention, US covid 19 graph - CDC daily new case, 2020 https://www.cdc.gov/coronavirus/2019-ncov/cases-updates/ca ses-in-us.html, Accessed July 28, 2020.

[14] Zhang X, Daniel Lin, Hugh Pforsich, and Lin VW. Physician workforce in the United States of America: forecasting nationwide shortages Human Resources for Health, 2020, 18, 8. 
[15] Zhang X, Daniel Tai, Hugh Pforsich, and Lin VW. United States Registered Nurse Workforce Report Card and Shortage Forecast: A Revisit, American Journal of Medical Quality, 2018, 33 (3), 229-236.

[16] Juraschek SP, Zhang X, Ranganathan VK and Lin VW. US Registered Nurse Workforce Report Card and Shortage Forecast, American Journal of Medical Quality, 27 (3) $241-$ 249, 2012.

[17] Testing hub of Johns Hopkins University, Which U.S state meet WHO recommended testing criteria? https://coronavirus.jhu.edu/testing/testing-positivity, Accessed July 28, 2020.

[18] Office of the Governor of Louisiana, Gov. Edwards Orders Statewide Mask Mandate, Closes Bars to On Premises Consumption as COVID-19 Continues to Spread Across Louisiana,

https://gov.louisiana.gov/index.cfm/newsroom/detail/2591, Accessed July 28, 2020.

[19] Reinhart E, Chen D. Incarceration and its disseminations: COVID-19 pandemic lessons from Chicago's Cook County Jail. Health Aff (Millwood) 2020; Epub ahead of print.

[20] The New York Times. Coronavirus in the U.S.: Latest map and case count. New York Times. 2020.

[21] Marcus JE, Frankel DN, Pawlak MT, et al. COVID-19 Monitoring and Response Among U.S. Air Force Basic Military Trainees - Texas, March-April 2020. MMWR Morb Mortal Wkly Rep 2020; 69: 685-688. DOI: http://dx.doi.org/10.15585/mmwr.mm6922e2

[22] Husch Blackwell, State-by-State Daily Updates Archive, https://www.huschblackwell.com/state-by-state-daily-updatesarchive, Accessed July 28, 2020.

[23] Wortham JM, Lee JT, Althomsons S, et al. Characteristics of Persons Who Died with COVID-19 - United States, February 12-May 18, 2020. MMWR Morb Mortal Wkly Rep 2020; 69: 923-929. DOI:

http://dx.doi.org/10.15585/mmwr.mm6928e1 external icon

[24] Burke RM, Killerby ME, Newton S, et al. Symptom Profiles of a Convenience Sample of Patients with COVID-19 - United States, January-April 2020. MMWR Morb Mortal Wkly Rep 2020; 69: 904-908. DOI:

http://dx.doi.org/10.15585/mmwr.mm6928a2external icon

[25] Grant MC, Geoghegan L, Arbyn M, et al. The prevalence of symptoms in 24,410 adults infected by the novel coronavirus (SARS-CoV-2; COVID-19): A systematic review and meta-analysis of 148 studies from 9 countries. PLoS One. 2020; 15 (6): e0234765. Published 2020 Jun 23. doi: 10.1371/journal.pone.023476530.

[26] Anne Alnor, MD, Maria B Sandberg, PhD, Charlotte Gils, MD, Pernille J Vinholt, MD, PhD, Laboratory tests and outcome for patients with COVID-19: A systematic review and meta-analysis, The Journal of Applied Laboratory Medicine,, jfaa098, https://doi.org/10.1093/jalm/jfaa098

[27] Tahvildari A, Arbabi M, Farsi Y, Jamshidi P, et al, Clinical Features, Diagnosis, and Treatment of COVID-19 in Hospitalized Patients: A Systematic Review of Case Reports and Case Series, Front Med (Lausanne). 2020; 7: 231.

[28] Dufort EM, Koumans EH, Chow EJ, et al. Multisystem Inflammatory Syndrome in Children in New York State. N
Engl J Med. 2020; 383 (4): 347-358. doi: 10.1056/NEJMoa2021756.

[29] Wichmann D, Sperhake JP, Lütgehetmann M, et al. Autopsy Findings and Venous Thromboembolism in Patients With COVID-19 [published online ahead of print, 2020 May 6]. Ann Intern Med. 2020; M20-2003. doi: 10.7326/M20-2003.

[30] Folegatti PM, Ewer KJ, Aley PK et al,, on behalf of the Oxford COVID Vaccine Trial Group $\uparrow$ Safety and immunogenicity of the ChAdOx1 nCoV-19 vaccine against SARS-CoV-2: a preliminary report of a phase $1 / 2$, single-blind, randomised controlled trial, Lancet, Published: July 20, 2020 DOI: https://doi.org/10.1016/S0140-6736(20)31604-4

[31] Zhu FC, Li YH, Guan XH, et al. Safety, tolerability, and immunogenicity of a recombinant adenovirus type- 5 vectored COVID-19 vaccine: a dose-escalation, open-label, non-randomised, first-in-human trial. Lancet. 2020; 395 (10240): 1845-1854. doi: 10.1016/S0140-6736(20)31208-3

[32] Zhu FC, Guan XH, Li YH et al, Immunogenicity and safety of a recombinant adenovirus type-5-vectored COVID-19 vaccine in healthy adults aged 18 years or older: a randomised, double-blind, placebocontrolled, phase 2 trial, Lancet, July 20, 2020 https://doi.org/10.1016/ S0140-6736(20)31605-6

[33] LA Jackson et al. ASARS-CoV-2 mRNA vaccine preliminary report. New England Journal of Medicine. DOI: 10.1056/NEJMoa2022483 (2020).

[34] Kellam P, Barclay W, The dynamics of humoral immune responses following SARS-CoV-2 infection and the potential for reinfection, J General Virology, 20 May 2020 https://doi.org/10.1099/jgv.0.001439

[35] Soo YO, Cheng Y, Wong R, et al. Retrospective comparison of convalescent plasma with continuing high-dose methylprednisolone treatment in SARS patients. Clin Microbiol Infect. 2004; 10 (7): 676-678. doi: 10.1111/j.1469-0691.2004.00956.x.

[36] Bhagavathula AS, Aldhaleei W, Rovetta A, and Rahmani J. Vaccines and drug therapeutics to lock down novel coronavirus disease 2019 (COVID-19): A systematic review of clinical trials. Cureus, published May 28, 2020; DOI: 10.7759/cureus.8342 (open access review article).

[37] Beigel JH, Tomashek KM, Dodd LE, et al. Remdesivir for the Treatment of Covid-19 - Preliminary Report [published online ahead of print, 2020 May 22]. N Engl J Med. 2020; NEJMoa2007764. doi: 10.1056/NEJMoa2007764.

[38] Zhang JJY, Lee KS, Ang LW, Leo YS, Young BE. Risk Factors of Severe Disease and Efficacy of Treatment in Patients Infected with COVID-19: A Systematic Review, Meta-Analysis and Meta-Regression Analysis [published online ahead of print, 2020 May 14]. Clin Infect Dis. 2020; ciaa576. doi: 10.1093/cid/ciaa576.

[39] VT Chandrasekar, B Venkatesalu, HK Patel, M Spadaccini, J Manteuffel, and M Ramesh Systematic review and meta-analysis of effectiveness of treatment options against SARS-CoV-2 infection, Journal of Medical Virology, (first published on July 15,2020 ) https://doi.org/10.1002/jmv.26302

[40] RECOVERY Collaborative Group, Horby P, Lim WS, et al. Dexamethasone in Hospitalized Patients with Covid-19 Preliminary Report [published online ahead of print, $2020 \mathrm{Jul}$ 17]. N Engl J Med. 2020; 10.1056/NEJMoa2021436. doi: 10.1056/NEJMoa2021436. 
[41] Chu DK, Akl EA, Duda S, et al. Physical distancing, face masks, and eye protection to prevent person-to-person transmission of SARS-CoV-2 and COVID-19: a systematic review and meta-analysis. Lancet. 2020; 395 (10242): 1973-1987. doi: 10.1016/S0140-6736(20)31142-9. 